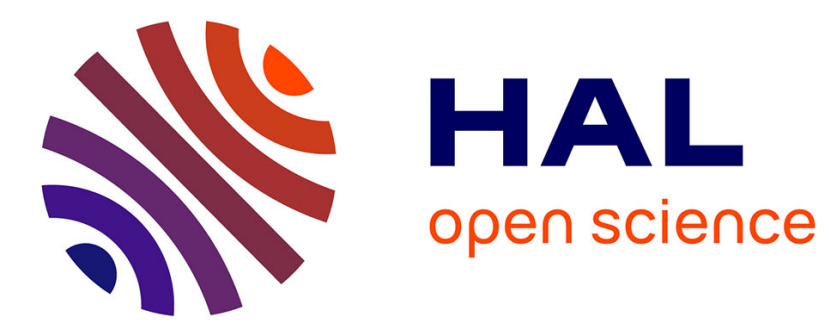

\title{
Altered zinc sensitivity of NMDA receptors harboring clinically-relevant mutations
}

Benjamin Serraz, Teddy Grand, Pierre Paoletti

\section{To cite this version:}

Benjamin Serraz, Teddy Grand, Pierre Paoletti. Altered zinc sensitivity of NMDA receptors harboring clinically-relevant mutations. Neuropharmacology, 2016, [Epub ahead of print]. 10.1016/j.neuropharm.2016.06.008 . inserm-01331195

\section{HAL Id: inserm-01331195 https://www.hal.inserm.fr/inserm-01331195}

Submitted on 13 Jun 2016

HAL is a multi-disciplinary open access archive for the deposit and dissemination of scientific research documents, whether they are published or not. The documents may come from teaching and research institutions in France or abroad, or from public or private research centers.
L'archive ouverte pluridisciplinaire HAL, est destinée au dépôt et à la diffusion de documents scientifiques de niveau recherche, publiés ou non, émanant des établissements d'enseignement et de recherche français ou étrangers, des laboratoires publics ou privés. 


\section{Accepted Manuscript}

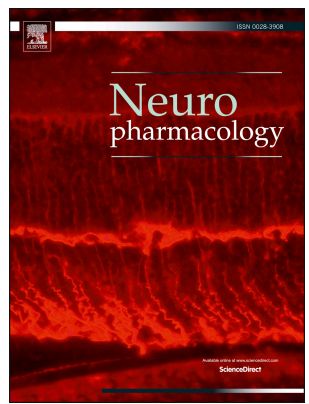

PII:

S0028-3908(16)30248-9

DOI:

10.1016/j.neuropharm.2016.06.008

Reference: NP 6334

To appear in: Neuropharmacology

Received Date: 22 March 2016

Revised Date: 17 May 2016

Accepted Date: 6 June 2016

Please cite this article as: Serraz, B., Grand, T., Paoletti, P., Altered zinc sensitivity of NMDA receptors harboring clinically-relevant mutations, Neuropharmacology (2016), doi: 10.1016/ j.neuropharm.2016.06.008.

This is a PDF file of an unedited manuscript that has been accepted for publication. As a service to our customers we are providing this early version of the manuscript. The manuscript will undergo copyediting, typesetting, and review of the resulting proof before it is published in its final form. Please note that during the production process errors may be discovered which could affect the content, and all legal disclaimers that apply to the journal pertain. 


\title{
Altered zinc sensitivity of NMDA receptors harboring clinically- relevant mutations
}

\author{
Benjamin Serraz, Teddy Grand and Pierre Paoletti \\ Ecole Normale Supérieure, PSL Research University, CNRS, INSERM \\ Institut de Biologie de l'École Normale Supérieure (IBENS) \\ F-75005 Paris, France
}

Correspondence to: Dr. Pierre Paoletti, Institut de Biologie de l'ENS, Ecole Normale Supérieure, 46 rue d'Ulm, 75005 Paris (pierre.paoletti@ens.fr)

\section{Acknowledgments}

This work was supported by the Fondation pour la Recherche Médicale ('Equipe FRM' grant DEQ2000326520 to PP), the French government ('Investissements d'Avenir' ANR-10-LABX54 MEMO LIFE and ANR-11-IDEX-0001-02 PSL* Research University), and by the University Pierre-et-Marie-Curie (UPMC Paris 6; fellowship to BS). The authors declare no competing financial interests. We thank Laurine Bonet for preparing cultured hippocampal neurons.

The authors declare no competing financial interests.

Key words: glutamate receptor; NMDA receptor; zinc; mutation; synapse; epilepsy

Abbreviated title: Impaired zinc sensitivity in mutant NMDARs 


\section{Abstract}

Recent human genetic studies have identified a surprisingly high number of alterations in genes encoding NMDA receptor (NMDAR) subunits in several common brain diseases. Among NMDAR subunits, the widely-expressed GluN2A subunit appears particularly affected, with tens of de novo or inherited mutations associated with neurodevelopmental conditions including childhood epilepsies and cognitive deficits. Despite the increasing identification of NMDAR mutations of clinical interest, there is still little information about the effects of the mutations on receptor and network function. Here we analyze the impact on receptor expression and function of nine GluN2A missense (i.e. single-point) mutations targeting the $\mathrm{N}$-terminal domain, a large regulatory region involved in subunit assembly and allosteric signaling. While several mutations produced no or little apparent effect on receptor expression, gating and pharmacology, two showed a drastic expression phenotype and two resulted in marked alterations in the sensitivity to zinc, a potent allosteric inhibitor of GluN1/GluN2A receptors and modulator of excitatory synaptic transmission. Surprisingly, both increase (GluN2A-R370W) and decrease (GluN2A-P79R) of zinc sensitivity were observed on receptors containing either one or two copies of the mutated subunits. Overexpression of the mutant subunits in cultured rat neurons confirmed the results from heterologous expression. These results, together with previously published data, indicate that disease-causing mutations in NMDARs produce a wide spectrum of receptor alterations, at least in vitro. They also point to a critical role of the zinc-NMDAR interaction in neuronal function and human health. 


\section{Introduction}

With the advent of massive sequencing technologies and whole-genome analysis, recent years have seen an explosion of data linking specific gene alterations to human brain disorders. A new and rather unexpected outcome from these sequencing efforts has been the surprisingly high number of mutations discovered in NMDA receptor (NMDAR) genes, most particularly in GRIN2A, the gene which encodes the GluN2A subunit and which accounts for $>80 \%$ of all the disease-linked mutations identified in ionotropic glutamate receptor (iGluR) subunits (Burnashev and Szepetowski, 2015; Soto et al., 2014; Yuan et al., 2015). The GluN2A subunit appears to be a key locus for multiple neurodevelopmental phenotypes, of which seizures constitute the largest group (Burnashev and Szepetowski, 2015). Investigating how these mutations identified in patients affect receptor function, circuit behavior and ultimately pathogenesis remains a largely unmet challenge.

NMDARs are widely expressed in the CNS where they are critically involved in many processes such as learning and memory. Functional disturbances of these receptors are also implicated in various neurological and psychiatric disorders. Overactivation of NMDARs can promote seizures and neuronal death, while NMDAR hypofunction has emerged as a leading hypothesis for schizophrenia (Paoletti et al., 2013). There is thus considerable interest in better understanding NMDARs and factors that control their expression and activation. At the molecular level, NMDARs are hetero-tetramers usually associating two GluN1 and two GluN2 subunits, of which there are four subtypes (GluN2A-D) (Glasgow et al., 2015; Paoletti et al., 2013; Wyllie et al., 2013). NMDARs form massive complexes with a typical layered organization comprising distal N-terminal domains (NTDs) and agonist-binding domains (ABDs) directly connected to the transmembrane pore region (TMD) (Figure 1A) (Karakas and Furukawa, 2014; Lee et al., 2014). Besides their key roles in subunit assembly, the NTDs endow NMDARs with unique signaling capacities, harboring binding sites for small ligands acting as subunit-specific allosteric modulators of ion channel activity (Hansen et al., 2010; Paoletti, 2011). In particular, the GluN2A NTD confers an exquisite sensitivity to zinc 
ions which are concentrated and released at many excitatory synapses where they act as powerful regulators of glutamatergic transmission (Kalappa et al., 2015; Vergnano et al., 2014; Vogt et al., 2000).

Here, we analyze the functional consequences of several missense mutations in NMDARs identified in children with rolandic epilepsies and encephalopathies associated with aphasia (Lemke et al., 2013; Lesca et al., 2013). We concentrate on mutations clustering in the N-terminal region of the GluN2A subunit. Our in vitro studies on recombinant receptors reveal variable phenotypes including distinct alterations in expression level and zinc sensitivity. 


\section{Material and methods}

\subsection{Molecular Biology}

The pcDNA3-based plasmids for rodent NMDAR subunits (rat GluN1-1a, named GluN1 herein; rat GluN2A; mouse GluN2B), the site-directed mutagenesis and sequencing procedures have been previously described(Mony et al., 2011). cRNAs were synthesized in vitro using a T7 transcription kit (Ambion). Selective expression of triheteromeric NMDARs was performed as previously described (Stroebel et al., 2014). The strategy employed is based on the use of ectopic retention signals from GABA-B receptors allowing control of NMDAR trafficking such that only triheteromeric receptors are expressed at the cell surface (co-expressed diheteromers being retained intracellularly). In experiments presented in Figure 3, the following subunits were used: GluN2A-r2, GluN2B-r2, GluN2A-P79R-r1, GluN2A-r3780W-r1, where $r 1$ and $r 2$ are retention signals derived from GABA-B1 and GABAB2 subunits, respectively (see (Stroebel et al., 2014)). As control experiments, we verified that co-expression of GluN1+GluN2Ar2 or GluN1+GluN2B-r2 or GluN1+GluN2A-P79R-r1 or GluN1+GluN2A-R370W-r1 subunits resulted in an almost complete lack of receptor expression (no, or very tiny ( $\leq 30 \mathrm{nA}$ ), NMDAR-mediated currents; $n=11-23$ oocytes for each condition), as expected if the corresponding diheteromeric receptors are efficiently retained in the ER. In contrast, following co-expression of $r 1$ and $r 2$ subunits, large currents (>0.5 $\mu \mathrm{A}$; up to $7 \mu \mathrm{A}$ ) were routinely measured indicating efficient cell surface expression of triheteromeric receptors.

\subsection{Electrophysiology}

Oocytes from female Xenopus laevis were prepared and voltage-clamped as described previously(Mony et al., 2011). Oocyte harvest was performed in accordance with the European directives 2010/63/EU on the Protection of Animals used for Scientific Purposes and in the framework of project authorization \#05137.02 as delivered by the competent 
French authorities. Each oocyte was coinjected with a mixture of GluN1:GluN2 cDNAs (or mRNAs) each at concentration of $15-50 \mathrm{ng} / \mu \mathrm{L}$ and at a ratio of $1: 1$ for diheteromers and 1:1:1 for triheteromers. Data were collected using pClamp10 and analyzed using Kaleidagraph4. The standard external solution contained (in mM): $100 \mathrm{NaCl}, 2.5 \mathrm{KCl}, 0.3$ $\mathrm{BaCl}_{2}, 5$ HEPES, 0.01 DTPA (diethylenetriamine-pentaacetic acid), $\mathrm{pH}$ 7.3. For $\mathrm{pH}$ experiments, an HEPES-enriched external medium was used (Gielen et al., 2008). For zinc experiments, DTPA was omitted (except in the '0' no-added zinc solution) and tricine (10 $\mathrm{mM}$ ) or ADA (N-(2-Acetamido)iminodiacetic acid, $1 \mathrm{mM}$ ) used to buffer zinc (Gielen et al., 2008). ADA was specifically used for mutant GluN2A-R370W receptors which display very high (i.e. sub-nanomolar) zinc sensitivity. Free zinc concentrations were calculated using the following relationships (Fayyazuddin et al., 2000; Paoletti et al., 1997): for tricine, $[Z n]_{\text {rree }}=[Z n]_{\text {added }} / 200$; for ADA, $[Z n]_{\text {rree }}=[Z n]_{\text {added }} / 17000$. NMDAR-mediated currents were induced by co-application of saturating concentrations of L-glutamate and glycine $(100 \mu \mathrm{M}$ each). Recordings were performed at $-60 \mathrm{mV}$ and at room temperature.

Whole-cell patch-clamp recordings were performed on HEK293 cells and primary cultures of neonatal $(\mathrm{P} 0)$ rat hippocampal neurons. Neurons were transfected with GluN2A and eGFP (0.8 $\mu \mathrm{g} / \mathrm{ml}$ each) at DIV4 using Lipofectamine 2000 (Life Technologies), and recorded at DIV5-6. HEK293 cells were transfected with GluN1, GluN2A and eGFP (0.5 $\mu \mathrm{g} / \mathrm{ml}$ each) using Polyethylenimine (Sigma), and recorded 24-48 hours later. The external solution contained (in mM): $140 \mathrm{NaCl}, 2.8 \mathrm{KCl}, 1 \mathrm{CaCl}_{2}, 10 \mathrm{HEPES}, 10$ tricine, 10 glucose (290-300 mOsm). The pipette solution contained (in mM): 115 CsF, 10 CsCl, 10 HEPES, 10 BAPTA (270-290 mOsm). Tricine was used to buffer zinc as described above. In the zinc washout kinetic experiments, tricine was present throughout. Currents were sampled at 10 $\mathrm{kHz}$ and low-pass filtered at $2 \mathrm{kHz}$ using an Axopatch $200 \mathrm{~B}$ amplifier and pClamp10.5. Agonists $(100 \mu \mathrm{M}$ glutamate $+100 \mu \mathrm{M}$ glycine for HEK cells; $300 \mu \mathrm{M}$ NMDA + $50 \mu \mathrm{M}$ Dserine for neurons) were applied using a multibarrel rapid solution exchanger (RSC 200; Bio- 
Logic). Recordings were performed at $-60 \mathrm{mV}$ for HEK cells and $-65 \mathrm{mV}$ for neurons, and at room temperature.

\subsection{Pharmacology and data analysis}

Glutamate and glycine dose-response curve (DRC) experiments were performed in the presence of $100 \mu \mathrm{M}$ of the respective co-agonist. Agonist DRCs were fitted with the following Hill equation: $I_{\text {rel }}=1 /\left(1+\left(E_{50} /[A]\right)^{n+H}\right)$, with $E_{50}$ and $n_{H}$ as free parameters. Determination of MK-801 inhibition time constant $\left(\tau_{\text {on }}\right)$ was performed as in Mony et al. (2011). MK-801 was applied at $10 \mathrm{nM}$. Proton DRCs were analyzed and fitted as in (Gielen et al., 2008), with $\mathrm{pH}_{\mathrm{IC50}}$ and $\mathrm{n}_{\mathrm{H}}$ as free parameters. Zinc DRCs were fitted with the following equation: $\mathrm{I}_{\mathrm{rel}}=1$ $\mathrm{a} /\left(1+\left(\mathrm{IC}_{50} /[\mathrm{C}]\right)^{\mathrm{nH}}\right)$, where $\mathrm{a}$ is the maximal inhibition, and with $\mathrm{IC}_{50}$, a and $\mathrm{n}_{\mathrm{H}}$ as free parameters. Zinc dissociation kinetics were fitted by single exponentials as previously performed (Paoletti et al., 1997).

\subsection{Immunoblotting}

Samples for immunoblots were obtained from cRNA-injected oocytes. Two oocytes per condition were used. Samples were prepared and immunoblots performed as previously described(Mony et al., 2011), except that electrophoresis was done in reducing conditions (5\% $\beta$-mercaptoethanol). The following antibodies were used: anti-GluN1 antibody (1:500, mouse monoclonal clone MAB363; Millipore), anti-GluN2A antibody (1:500, rabbit monoclonal clone A12W; Millipore), anti- $\alpha$ Tubuline (1:1000, mouse monoclonal clone DM1A; Upstate), secondary goat peroxidase-conjugated anti-mouse antibody $(1: 10,000$, Jackson ImmunoResearch, \#115-035-003) or secondary rabbit peroxidase-conjugated anti-goat antibody (1:10,000, Jackson ImmunoResearch, \#305-035-003). 


\subsection{Statistical analysis}

Analysis of statistical significance was assessed using either the two sample t-test (Figure $3 \mathrm{E}, \alpha=0.01$ ) or the Bonferroni-corrected two-tailed post hoc $\mathrm{t}$-test (Figures $1 \mathrm{~B}, \alpha=0.0011$; Figure $2 B, \alpha=0.0014)$. Error bars represent the standard deviation of the mean value (SD). 


\section{Results}

While GRIN2A mutations identified in patients with neurodevelopmental and psychiatric disorders scatter throughout the subunit's domains, we decided to focus on mutations that locate in the receptor's N-terminal region. The membrane-distal GluN2 NTD together with the short connecting linker to the ABDs control a surprisingly diverse set of receptor functions including subunit assembly, channel open probability and allosteric regulation, rendering this region a target of therapeutic interest (Farina et al., 2011; Gielen et al., 2009; Hansen et al., 2010; Herguedas et al., 2013; Mony et al., 2011; Yuan et al., 2009). Based on two recent clinical reports (Lemke et al., 2013; Lesca et al., 2013), nine GluN2A cDNA single-point mutations associated with various epilepsy-cognitive phenotypes were generated (P79R, F183I, I184S, C231Y, A243V, A290V, G295S, R370W and C436R) and the resulting GluN2A-containing receptors studied in heterologous expression systems. All mutations locate in the NTD, except for C436R which resides in the ABD but in close proximity to the NTD lower lobe (Figure 1A). The genetic origin of these mutations are either inherited (P79R, F183I, I184S, C231Y), de novo (C436R) or of unknown inheritance (A243V, A290V, G295S, R370W) (Lemke et al., 2013; Lesca et al., 2013).

\subsection{Effects of the mutations on receptor expression}

To investigate the impact of the mutations on receptor expression and function, we first used Xenopus oocytes as a heterologous expression system. Both wild-type (wt) GluN1 and wt or mutant GluN2A subunits were injected in oocytes, and cells subsequently tested for NMDARmediated currents using two-electrode voltage-clamp recordings. For the majority of mutant receptors (F183I, I184S, A243V, A290V, G295S, R370W), currents of large amplitude, comparable to that of wt receptors, were recorded (Figure 1B). In contrast, for the three remaining mutants, currents were either markedly diminished (P79R) or vanishingly small (C231Y, C436R). Western blots revealed that the decrease in functionality was likely due to 
a deficiency in GluN2A subunit expression (Figure 1C). Surprisingly, in the case of the GluN2A-C436R cysteine mutation, immunoblotting with GluN1 antibody also revealed a major drop in GluN1 subunit expression (Figure 1C). Patch-clamp experiments in mammalian HEK293 cells confirmed these strong expression phenotypes (current density of: $231 \pm 153 \mathrm{pA} / \mathrm{pF}[\mathrm{n}=6]$ for wt receptors; $43 \pm 42 \mathrm{pA} / \mathrm{pF}[\mathrm{n}=6]$ for P79R; no current detected for both C231Y [n=6] and C436R [n=6]). Thus, the three GluN2A missense mutations, C231Y, C436R, and to a lesser extent P79R, result in a marked expression phenotype likely involving impaired GluN subunit folding and/or assembly. For those mutations that yielded functional receptors, we next investigated the gating and pharmacological attributes of the mutated receptors.

\subsection{GluN2A NTD mutations have minimal effect on the receptor gating properties}

GluN2 subunits are the major determinants of NMDAR functional diversity imparting distinct biophysical and pharmacological properties (Glasgow et al., 2015; Paoletti et al., 2013; Wyllie et al., 2013). In particular, the GluN2A subunit endows NMDARs with relatively high open channel probability and relatively low affinity to glutamate and to the co-agonist glycine. We first examined whether glutamate and glycine sensitivity were altered in mutant receptors. On the seven mutant receptors tested, full dose-response curve experiments revealed no or very modest effect on both glutamate and glycine sensitivity $(\leq 1.5$ fold change

in $\mathrm{EC}_{50}$; Figure 1D-E, Table 1). We next estimated the channel maximal open probability (Po) by measuring kinetics of current inhibition by MK-801, a method classically used to index receptor channel Po (Rosenmund et al., 1993; Zhu et al., 2013). Again, no significant difference between wt and the seven mutant receptors was observed (Figure 1F, Table 1). Thus, the single-point GluN2A mutations P79R, F183I, I184S, A243V, A290V, G295S and R370W minimally impact the basal receptor activation properties. 


\subsection{Mutations GluN2A-P79R and GluN2A-R370W alter zinc sensitivity}

A hallmark of NMDARs is their ability to be modulated by an array of small extracellular ligands, either synthetic or endogenous, acting as subunit-specific allosteric modulators (Paoletti et al., 2013). Among them, zinc ions have triggered particular interest since they are enriched and released at many glutamatergic synapses (Paoletti et al., 2009) and exert potent inhibition of NMDARs by selectively binding to a site in the GluN2A NTD (Hansen et al., 2010; Vergnano et al., 2014). Because our selected mutations target this domain, we assessed zinc sensitivity of each mutant receptor by performing full zinc inhibitory doseresponse curve using zinc-buffered solutions. Two mutant receptors out of the seven tested displayed clear phenotypes (Figure 2A-B, Table 1). P79R mutant receptors displayed decreased zinc sensitivity reflected as an increase in zinc $\mathrm{IC}_{50}$ (44 nM vs $12.7 \mathrm{nM}$ for wt receptors) and a decreased level of maximal inhibition (48\% vs $77 \%$ ). Conversely, R370W receptors displayed greatly enhanced zinc sensitivity mostly reflected by a $>10$-fold decrease in zinc $\mathrm{IC}_{50}(0.87 \mathrm{nM}$ vs $12.7 \mathrm{nM})$.

To gain further insights into the effects of the mutations on the zinc-receptor interaction, we performed fast zinc concentration jumps on transfected HEK cells and measured current relaxations upon zinc washout (i.e. zinc dissociation kinetics). Compared to wt receptors, offrelaxations were faster for P79R receptors but slower for R370W receptors $\left(\tau_{\text {off }}=1.0 \pm 0.2 \mathrm{~s}\right.$ [n=8] and $5.2 \pm 1.3 \mathrm{~s}[\mathrm{n}=11]$, respectively, vs $1.6 \pm 0.3 \mathrm{~s}[\mathrm{n}=10]$ for wt; Figure $2 \mathrm{C})$, in good agreement with the respective decrease and increase in zinc sensitivity observed at steadystate conditions. These results indicate that the shift in zinc affinity $\left(\mathrm{IC}_{50}\right)$ induced by the mutations are attributable, at least in part, to a difference in residency time of zinc on its GluN2A NTD site.

Inhibition of GluN2A NMDARs by zinc is strongly pH-dependent, such that zinc sensitivity increases with increased proton concentrations (and vice-versa) (Choi and Lipton, 1999; Gielen et al., 2008; Low et al., 2000). Accordingly, we next investigated the pH 
sensitivity of all seven mutant receptors including GluN2A-P79R and GluN2A-R370W. Compared to wt receptors, no major change in $\mathrm{pH}$ sensitivity was observed for any of the mutants $\left(\Delta \mathrm{pH}_{\mathrm{IC} 50} \leq 0.2 \mathrm{pH}\right.$ unit; Figure $\left.2 \mathrm{D}\right)$. The largest change was observed for GluN2AP79R receptors which, surprisingly, showed enhanced proton sensitivity despite their decreased zinc sensitivity. To our knowledge, this absence of correlation between proton and zinc sensitivities is unprecedented and points to a unique and specific role of residue GluN2A-P79 in controlling intersubunit allosteric signaling (see Discussion).

\subsection{Impact of mutation copy number on receptor function}

In vivo, NMDARs exist as multiple subtypes that differ in their subunit composition, being either diheteromeric (two identical GluN2 subunits) or triheteromeric (two distinct GluN2 subunits) (Paoletti et al., 2013). Since all clinical GRIN2A mutations identified to date are heterozygous (Burnashev and Szepetowski, 2015), mixtures of NMDAR populations are likely to co-exist in patients carrying the disease-causing mutation. Therefore, we aimed at investigating the properties of triheteromeric NMDARs, containing a single copy of the mutated GluN2A subunits combined with either a wt GluN2A subunit or a wt GluN2B subunit (GluN1/GluN2Awt/GluN2Amutant and GluN1/GluN2Amutant/GluN2Bwt receptors, respectively). This later subunit was chosen because triheteromeric GluN1/GluN2A/GluN2B receptors constitute one of the most abundant NMDAR subtypes in the forebrain (Paoletti et al., 2013).

To selectively express triheteromeric NMDARs at the surface of Xenopus oocytes, we employed the methodology recently developed in our laboratory based on ectopic retention signals (Stroebel et al., 2014). We first verified that diheteromeric receptors containing two copies of the GluN2 subunit with the transplanted retention signals were properly retained in the ER (see Methods). In contrast, for triheteromeric receptors, large ( $>0.5 \mu A)$ NMDARmediated currents were routinely obtained. For both GluN2A-P79R and GluN2A-R370W 
mutations, triheteromeric GluN1/GluN2Awt/GluN2Amutant receptors displayed zinc sensitivity intermediate between that of wt or doubly-mutated diheteromeric receptors (Figure 3A,C). Similarly, a single mutant GluN2A-R370W subunit, when paired with a wt GluN2B subunit that harbors a low $\mu \mathrm{M}$ zinc binding site in its NTD (Karakas et al., 2009; Rachline et al., 2005), confers unique zinc sensitivity, distinct from both parent diheteromeric GluN1/GluN2 receptors and from wt triheteromeric GluN1/GluN2A/GluN2B receptors (Figure 3D). For GluN2A-P79R, the reduced zinc sensitivity conferred by the mutant GluN2A subunit was such that the zinc sensitivity of receptors containing one mutant GluN2A subunit and one wt GluN2B subunit was almost indistinguishable of that of receptors composed of two identical mutant GluN2A subunits (Figure 3B). Altogether, these results demonstrate that a single copy of the GluN2A mutation is sufficient to alter the receptor's zinc sensitivity irrespective of the pairing GluN2 subunit. We thus anticipate that the majority of GluN2Acontaining NMDARs in patients will display aberrant modulation by extracellular zinc.

\subsection{Disrupted zinc sensitivity of mutant receptors expressed in neurons}

The above results show that mutant GluN2A-P79R and GluN2A-R370W receptors display altered interaction with the allosteric inhibitor zinc in recombinant expression systems. To verify that this is also the case in a more native environment, we overexpressed wt or mutated GluN2A subunits in rat hippocampal cultured neurons and assessed sensitivity of NMDAR-mediated responses to zinc applications. Neurons overexpressing GluN2A-P79R subunits showed decreased inhibition of NMDAR-mediated currents to $20 \mathrm{nM}$ zinc compared to neurons overexpressing wt GluN2A subunits $(4 \pm 11 \%[n=8]$ vs $16 \pm 7 \%$ inhibition [n=7] ; Figure 3E). In contrast, neurons transfected with GluN2A-R370W subunits displayed marked zinc inhibition at a very low zinc concentration ( $2 \mathrm{nM})$ while only modest inhibition was observed for wt GluN2A overexpressing neurons ( $37 \pm 8 \%$ inhibition [ $n=6$ ] vs $16 \pm 5 \%$ $[n=10]$; Figure 3E). Overall, these results support our findings on heterologously expressed 
NMDARs and confirm that the altered zinc sensitivity of GluN2A-P79R and GluN2A-R370W receptors is a salient feature of these receptors encoding disease-causing mutations. 


\section{Discussion}

By studying recombinant NMDARs expressed in heterologous systems and primary cultured neurons, we reveal that disease-linked mutations targeting the GluN2A N-terminal region produce distinct sets of receptor alterations that manifest either as impaired receptor expression or altered modulation by extracellular zinc (or a combination of both). These findings have implications both for NMDAR physiology and the underlying pathogenic mechanisms in patients with GRIN2A mutations.

Clinically-relevant GRIN2A mutations are spread across all NMDAR domains hinting to diverse impacts on receptor structure, abundance, localization and function. In agreement, TMD missense mutations have been shown to affect channel permeation (Endele et al., 2010), while $A B D$ and $A B D-T M D$ linker mutations specifically alter channel gating kinetics (Carvill et al., 2013; Lesca et al., 2013; Yuan et al., 2014). We now show that GluN2A mutations targeting the $\mathrm{N}$-terminal region can also affect receptor function, yet through alternative mechanisms. We find that the two cysteine mutations C231Y and C436R, each leads to a drastic reduction in receptor expression. In vivo, this likely results in decreased receptor number and deficient NMDAR signaling, an effect also expected for nonsense, deletion and frameshift GRIN2A mutations identified in several patients (Burnashev and Szepetowski, 2015; Yuan et al., 2015). C231 sits within a buried hydrophobic cavity of the NTD lower lobe which likely does not tolerate a large hydroxyl-containing tyrosine residue. Therefore, we suggest that the C231Y mutation results in GluN2A misfolding and degradation. The GluN2A-C436R subunit is likely to share a similar destiny. By engaging in a disulfide bond with residue $\mathrm{C} 456, \mathrm{C} 436$ structures a large ABD loop specific to NMDARs (i.e. absent in other iGluRs). Our results now reveal that this loop has an essential role in GluN2A biogenesis, likely because of its extensive interactions with neighboring domains (Karakas and Furukawa, 2014; Lee et al., 2014; Regalado et al., 2001). 
Besides subunit expression, our results unveil that zinc modulation is another conspicuous NMDAR property that is profoundly modified by specific sets of disease-linked mutations. Two mutations were found to alter GluN2A-mediated high-affinity zinc inhibition: P79R and R370W. While P79R diminishes zinc inhibition through a combined decrease in zinc 'efficacy' (i.e. decreased maximal level of inhibition) and 'affinity' (i.e. increased ${ } C_{50}$ ), R370W enhances zinc inhibition mostly through an 'affinity' effect. Both residues locate away from the predicted zinc binding site in the GluN2A NTD interlobe cleft (Figure 4; Hansen et al., 2010; Paoletti, 2011), and likely mediate their effects on zinc sensitivity through distinct mechanisms. According to the GluN1/GluN2B NTD structure (Karakas et al., 2011), GluN2AR370 (which is conserved in GluN2B) interacts with a lower lobe loop which contains a residue critically involved in zinc binding (GluN2A-E266) (Figure 4A; Fayyazuddin et al., 2000). Substitution of the arginine by a bulky hydrophobic tryptophan may favor a loop conformation which fortuitously results in enhanced zinc coordination. Such an effect would account for the observed slowing down of the zinc dissociation kinetics (Figure 2C). We propose that the mutation P79R acts differently. The homologous proline in GluN2B (GluN2B-P80; conserved in all four GluN2 subunits) locates at the edge of GluN2 NTD and makes extensive hydrophobic contacts with the neighboring GluN1 NTD (Figure 4B; Karakas et al., 2011). Its replacement by a positively charged arginine likely disrupts this hydrophobic cluster. We thus hypothesize that in GluN2A receptors the P79R mutation affects zinc (and proton) sensitivity indirectly, at least in part, by altering NTD dimerization. We have no clear explanation for why this mutation, which decreases zinc sensitivity but enhances proton sensitivity, deviates from the rule that positively correlates proton and zinc sensitivity in GluN2A receptors (Choi and Lipton, 1999; Gielen et al., 2008; Low et al., 2000). We speculate that this unexpected result finds its origin both in the location of P79 at a specific subunit-subunit interface and in the nature of the substitution (a positively-charged arginine). The two factors may result in a reduced zinc-NTD interaction together with a 'distorted' GluN1-GluN2A NTD dimer configuration stabilizing a (proton favorable) inhibited state of the 
receptor. Whatever the scenario, our data further strengthen the importance of the subunitsubunit interfaces in controlling allosteric signaling in NMDARs, as hinted by previous structure-function studies (Gielen et al., 2008; Karakas et al., 2011; Low et al., 2003; Zhu et al., 2014; Zhu et al., 2013).

The fact that two mutations (P79R and R370W) with opposite effects in vitro (decreased and increased zinc inhibition, respectively) lead to overlapping clinical symptoms (Rolandic epilepsy) is puzzling. The lack of any obvious receptor abnormalities for a number of disease-linked mutations (F183I, I184S, A243V, A290V and G295S) is another apparent paradox. Several reasons make the genotype-phenotype correlation difficult. Although the causative role of certain GRIN2A mutations in the disease is well established, others may act as susceptibility risk factors rather than monogenic traits (Burnashev and Szepetowski, 2015; Yuan et al., 2015). Cell autonomous effects are another confounding factor. Overactivation of NMDARs in principal cells may lead to network hyperexcitability and promotes pro-epileptic effects, but a similar outcome is expected from too little NMDAR activity in inhibitory interneurons (Belforte et al., 2010). Finally, mutations may result in abnormal coupling of the receptors to downstream intracellular cascades (Hardingham and Bading, 2010), effects that escape electrophysiological measurements. We note that an apparent discrepancy between overlapping clinical phenotypes and genetic alterations of opposite sign (loss- and gain-offunction mutations) has already been described for SCN1A, another epilepsy gene (Marini et al., 2011). Obviously, much work remains to fully understand the circuit level pathology of GRIN2A mutations.

By showing specific impairments in the zinc sensitivity of NMDARs harboring clinically-relevant mutations, our results support the idea that impaired synaptic zinc homeostasis contributes to human pathology. Zinc concentrates at many excitatory synapses and, in animal models, can modulate synaptic plasticity, memory formation and seizure susceptibility (Paoletti et al., 2009; Sensi et al., 2011; Sindreu and Storm, 2011). In humans, impaired zinc-glycine receptor interaction may cause hyperekplexia (Zhou et al., 2013), while 
loss of the synaptic zinc transporter ZnT3 increases the risk of febrile seizures (Hildebrand et al., 2015). The emerging concept that synaptic zinc is an important neuromodulator and contributing factor in human brain physiopathology opens interesting possibilities for novel therapeutic interventions. 


\section{References}

Belforte, J. E., Zsiros, V., Sklar, E. R., Jiang, Z., Yu, G., Li, Y., Quinlan, E. M., Nakazawa, K., 2010. Postnatal NMDA receptor ablation in corticolimbic interneurons confers schizophrenialike phenotypes. Nat Neurosci 13, 76-83.

Burnashev, N., Szepetowski, P., 2015. NMDA receptor subunit mutations in neurodevelopmental disorders. Curr Opin Pharmacol 20, 73-82.

Carvill, G. L., Regan, B. M., Yendle, S. C., O'Roak, B. J., Lozovaya, N., Bruneau, N., Burnashev, N., Khan, A., Cook, J., Geraghty, E., Sadleir, L. G., Turner, S. J., Tsai, M. H., Webster, R., Ouvrier, R., Damiano, J. A., Berkovic, S. F., Shendure, J., Hildebrand, M. S., Szepetowski, P., Scheffer, I. E., Mefford, H. C., 2013. GRIN2A mutations cause epilepsyaphasia spectrum disorders. Nat Genet 45, 1073-1076.

Choi, Y. B., Lipton, S. A., 1999. Identification and mechanism of action of two histidine residues underlying high-affinity Zn2+ inhibition of the NMDA receptor. Neuron 23, 171-180.

Endele, S., Rosenberger, G., Geider, K., Popp, B., Tamer, C., Stefanova, I., Milh, M., Kortum, F., Fritsch, A., Pientka, F. K., Hellenbroich, Y., Kalscheuer, V. M., Kohlhase, J., Moog, U., Rappold, G., Rauch, A., Ropers, H. H., von Spiczak, S., Tonnies, H., Villeneuve, N., Villard, L., Zabel, B., Zenker, M., Laube, B., Reis, A., Wieczorek, D., Van Maldergem, L., Kutsche, K., 2010. Mutations in GRIN2A and GRIN2B encoding regulatory subunits of NMDA receptors cause variable neurodevelopmental phenotypes. Nat Genet 42, 1021-1026.

Farina, A. N., Blain, K. Y., Maruo, T., Kwiatkowski, W., Choe, S., Nakagawa, T., 2011. Separation of domain contacts is required for heterotetrameric assembly of functional NMDA receptors. J Neurosci 31, 3565-3579.

Fayyazuddin, A., Villarroel, A., Le Goff, A., Lerma, J., Neyton, J., 2000. Four residues of the extracellular N-terminal domain of the NR2A subunit control high-affinity $\mathrm{Zn} 2+$ binding to NMDA receptors. Neuron 25, 683-694.

Gielen, M., Le Goff, A., Stroebel, D., Johnson, J. W., Neyton, J., Paoletti, P., 2008. Structural rearrangements of NR1/NR2A NMDA receptors during allosteric inhibition. Neuron 57, 80-93.

Gielen, M., Siegler Retchless, B., Mony, L., Johnson, J. W., Paoletti, P., 2009. Mechanism of differential control of NMDA receptor activity by NR2 subunits. Nature 459, 703-707.

Glasgow, N. G., Siegler Retchless, B., Johnson, J. W., 2015. Molecular bases of NMDA receptor subtype-dependent properties. J Physiol 593, 83-95.

Hansen, K. B., Furukawa, H., Traynelis, S. F., 2010. Control of assembly and function of glutamate receptors by the amino-terminal domain. Mol Pharmacol 78, 535-549.

Hardingham, G. E., Bading, H., 2010. Synaptic versus extrasynaptic NMDA receptor signalling: implications for neurodegenerative disorders. Nat Rev Neurosci 11, 682-696.

Herguedas, B., Krieger, J., Greger, I. H., 2013. Receptor heteromeric assembly-how it works and why it matters: the case of ionotropic glutamate receptors. Prog Mol Biol Transl Sci 117, 361-386.

Hildebrand, M. S., Phillips, A. M., Mullen, S. A., Adlard, P. A., Hardies, K., Damiano, J. A., Wimmer, V., Bellows, S. T., McMahon, J. M., Burgess, R., Hendrickx, R., Weckhuysen, S., 
Suls, A., De Jonghe, P., Scheffer, I. E., Petrou, S., Berkovic, S. F., Reid, C. A., 2015. Loss of synaptic $\mathrm{Zn}(2+)$ transporter function increases risk of febrile seizures. Sci Rep 5, 17816.

Kalappa, B. I., Anderson, C. T., Goldberg, J. M., Lippard, S. J., Tzounopoulos, T., 2015. AMPA receptor inhibition by synaptically released zinc. Proc Natl Acad Sci U S A 112, 15749-15754.

Karakas, E., Furukawa, H., 2014. Crystal structure of a heterotetrameric NMDA receptor ion channel. Science 344, 992-997.

Karakas, E., Simorowski, N., Furukawa, H., 2009. Structure of the zinc-bound amino-terminal domain of the NMDA receptor NR2B subunit. EMBO J 28, 3910-3920.

Karakas, E., Simorowski, N., Furukawa, H., 2011. Subunit arrangement and phenylethanolamine binding in GluN1/GluN2B NMDA receptors. Nature 475, 249-253.

Lee, C. H., Lu, W., Michel, J. C., Goehring, A., Du, J., Song, X., Gouaux, E., 2014. NMDA receptor structures reveal subunit arrangement and pore architecture. Nature 511, 191-197.

Lemke, J. R., Lal, D., Reinthaler, E. M., Steiner, I., Nothnagel, M., Alber, M., Geider, K., Laube, B., Schwake, M., Finsterwalder, K., Franke, A., Schilhabel, M., Jahn, J. A., Muhle, H., Boor, R., Van Paesschen, W., Caraballo, R., Fejerman, N., Weckhuysen, S., De Jonghe, P., Larsen, J., Moller, R. S., Hjalgrim, H., Addis, L., Tang, S., Hughes, E., Pal, D. K., Veri, K., Vaher, U., Talvik, T., Dimova, P., Guerrero Lopez, R., Serratosa, J. M., Linnankivi, T., Lehesjoki, A. E., Ruf, S., Wolff, M., Buerki, S., Wohlrab, G., Kroell, J., Datta, A. N., Fiedler, B., Kurlemann, G., Kluger, G., Hahn, A., Haberlandt, D. E., Kutzer, C., Sperner, J., Becker, F., Weber, Y. G., Feucht, M., Steinbock, H., Neophythou, B., Ronen, G. M., GruberSedlmayr, U., Geldner, J., Harvey, R. J., Hoffmann, P., Herms, S., Altmuller, J., Toliat, M. R., Thiele, H., Nurnberg, P., Wilhelm, C., Stephani, U., Helbig, I., Lerche, H., Zimprich, F., Neubauer, B. A., Biskup, S., von Spiczak, S., 2013. Mutations in GRIN2A cause idiopathic focal epilepsy with rolandic spikes. Nat Genet 45, 1067-1072.

Lesca, G., Rudolf, G., Bruneau, N., Lozovaya, N., Labalme, A., Boutry-Kryza, N., Salmi, M., Tsintsadze, T., Addis, L., Motte, J., Wright, S., Tsintsadze, V., Michel, A., Doummar, D., Lascelles, K., Strug, L., Waters, P., de Bellescize, J., Vrielynck, P., de Saint Martin, A., Ville, D., Ryvlin, P., Arzimanoglou, A., Hirsch, E., Vincent, A., Pal, D., Burnashev, N., Sanlaville, D., Szepetowski, P., 2013. GRIN2A mutations in acquired epileptic aphasia and related childhood focal epilepsies and encephalopathies with speech and language dysfunction. Nat Genet 45, 1061-1066.

Low, C. M., Lyuboslavsky, P., French, A., Le, P., Wyatte, K., Thiel, W. H., Marchan, E. M., Igarashi, K., Kashiwagi, K., Gernert, K., Williams, K., Traynelis, S. F., Zheng, F., 2003. Molecular determinants of proton-sensitive N-methyl-D-aspartate receptor gating. Mol Pharmacol 63, 1212-1222.

Low, C. M., Zheng, F., Lyuboslavsky, P., Traynelis, S. F., 2000. Molecular determinants of coordinated proton and zinc inhibition of N-methyl-D-aspartate NR1/NR2A receptors. Proc Natl Acad Sci U S A 97, 11062-11067.

Marini, C., Scheffer, I. E., Nabbout, R., Suls, A., De Jonghe, P., Zara, F., Guerrini, R., 2011. The genetics of Dravet syndrome. Epilepsia 52 Suppl 2, 24-29. 
Mony, L., Zhu, S., Carvalho, S., Paoletti, P., 2011. Molecular basis of positive allosteric modulation of GluN2B NMDA receptors by polyamines. EMBO J 30, 3134-3146.

Paoletti, P., 2011. Molecular basis of NMDA receptor functional diversity. Eur J Neurosci 33, 1351-1365.

Paoletti, P., Ascher, P., Neyton, J., 1997. High-affinity zinc inhibition of NMDA NR1-NR2A receptors. J Neurosci 17, 5711-5725.

Paoletti, P., Bellone, C., Zhou, Q., 2013. NMDA receptor subunit diversity: impact on receptor properties, synaptic plasticity and disease. Nat Rev Neurosci 14, 383-400.

Paoletti, P., Vergnano, A. M., Barbour, B., Casado, M., 2009. Zinc at glutamatergic synapses. Neuroscience 158, 126-136.

Rachline, J., Perin-Dureau, F., Le Goff, A., Neyton, J., Paoletti, P., 2005. The micromolar zinc-binding domain on the NMDA receptor subunit NR2B. J Neurosci 25, 308-317.

Regalado, M. P., Villarroel, A., Lerma, J., 2001. Intersubunit cooperativity in the NMDA receptor. Neuron 32, 1085-1096.

Rosenmund, C., Clements, J. D., Westbrook, G. L., 1993. Nonuniform probability of glutamate release at a hippocampal synapse. Science 262, 754-757.

Sensi, S. L., Paoletti, P., Koh, J. Y., Aizenman, E., Bush, A. I., Hershfinkel, M., 2011. The neurophysiology and pathology of brain zinc. J Neurosci 31, 16076-16085.

Sindreu, C., Storm, D. R., 2011. Modulation of neuronal signal transduction and memory formation by synaptic zinc. Front Behav Neurosci 5, 68.

Soto, D., Altafaj, X., Sindreu, C., Bayes, A., 2014. Glutamate receptor mutations in psychiatric and neurodevelopmental disorders. Commun Integr Biol 7, e27887.

Stroebel, D., Carvalho, S., Grand, T., Zhu, S., Paoletti, P., 2014. Controlling NMDA receptor subunit composition using ectopic retention signals. J Neurosci 34, 16630-16636.

Vergnano, A. M., Rebola, N., Savtchenko, L. P., Pinheiro, P. S., Casado, M., Kieffer, B. L., Rusakov, D. A., Mulle, C., Paoletti, P., 2014. Zinc dynamics and action at excitatory synapses. Neuron 82, 1101-1114.

Vogt, K., Mellor, J., Tong, G., Nicoll, R., 2000. The actions of synaptically released zinc at hippocampal mossy fiber synapses. Neuron 26, 187-196.

Wyllie, D. J., Livesey, M. R., Hardingham, G. E., 2013. Influence of GluN2 subunit identity on NMDA receptor function. Neuropharmacology 74, 4-17.

Yuan, H., Hansen, K. B., Vance, K. M., Ogden, K. K., Traynelis, S. F., 2009. Control of NMDA receptor function by the NR2 subunit amino-terminal domain. J Neurosci 29, 1204512058.

Yuan, H., Hansen, K. B., Zhang, J., Pierson, T. M., Markello, T. C., Fajardo, K. V., Holloman, C. M., Golas, G., Adams, D. R., Boerkoel, C. F., Gahl, W. A., Traynelis, S. F., 2014. Functional analysis of a de novo GRIN2A missense mutation associated with early-onset epileptic encephalopathy. Nat Commun 5, 3251. 
Yuan, H., Low, C. M., Moody, O. A., Jenkins, A., Traynelis, S. F., 2015. Ionotropic GABA and Glutamate Receptor Mutations and Human Neurologic Diseases. Mol Pharmacol 88, 203217.

Zhou, N., Wang, C. H., Zhang, S., Wu, D. C., 2013. The GLRA1 missense mutation W170S associates lack of Zn2+ potentiation with human hyperekplexia. J Neurosci 33, 17675-17681.

Zhu, S., Riou, M., Yao, C. A., Carvalho, S., Rodriguez, P. C., Bensaude, O., Paoletti, P., Ye, S., 2014. Genetically encoding a light switch in an ionotropic glutamate receptor reveals subunit-specific interfaces. Proc Natl Acad Sci U S A 111, 6081-6086.

Zhu, S., Stroebel, D., Yao, C. A., Taly, A., Paoletti, P., 2013. Allosteric signaling and dynamics of the clamshell-like NMDA receptor GluN1 N-terminal domain. Nat Struct Mol Biol 20, 477-485. 


\section{Figure legends}

\section{Figure 1: Effects of GluN2A mutations on receptor expression and activation}

A. Cartoon representation of a GluN1/GluN2A receptor (left; only one of the two dimers is represented) and location of the studied GluN2A mutations (right; modeled structure of the GluN1/GluN2A NTD heterodimer based on the GluN1/GluN2B NTD crystal structure(Lee et al., 2014)). NTD, N-terminal domain; ABD, agonist-binding domain; TMD, transmembrane domain; CTD, C-terminal domain. Glu, glutamate; Gly, glycine. B. Box plot of current amplitudes of wild-type (wt) and mutant GluN2A receptors expressed in Xenopus oocytes. Number of cells: 67 (wt), 78 (P79R), 33 (F183I), 32 (I184S), 18 (C231Y), 70 (A243V), 35 (A290V), 37 (G295S), 62 (370W), 19 (C436R). *** $p=2.610^{-18}$ (P79R), $p=5.210^{-19}$ (C231Y), $\mathrm{p}=5.310^{-19}(\mathrm{C} 436 \mathrm{R})$, Bonferroni-corrected two-tailed post hoc t-test. C. Immunoblots from oocytes expressing wt and mutant GluN2A receptors. The band around $50 \mathrm{kDa}$ corresponds to $\alpha$-tubulin used as a loading control. * indicates non-specific bands seen with the antiGluN1 antibody. n.i., non-injected oocytes. D. Sensitivity to glutamate. E. Sensitivity to glycine. F. MK-801 inhibition kinetics. Values of MK-801 $\tau_{\mathrm{on}}$, dose-response curve fits and number of cells $(n)$ are listed in Table 1.

\section{Figure 2: Mutations GluN2A-P79R and GluN2A-R370W alter zinc sensitivity}

A. Zinc inhibition curves for wild-type (wt, green) and mutant (red, GluN2A-P79R; blue, GluN2A-R370W receptors; grey, others) receptors. Inset: Representative NMDAR trace currents showing zinc inhibition by 5,50 and $500 \mathrm{nM}$ zinc. B. Zinc $\mathrm{IC}_{50}$ values determined from the dose-response curves. ${ }^{* \star *}, p=0.00015$ (P79R, $\left.n=10\right), p=0.0000016$ (R370W, $\left.n=6\right)$, Bonferroni-corrected two-tailed post hoc t-test. C. Zinc off-relaxation kinetics measured in HEK293 cells (normalized current responses). Zinc (40 nM) is applied and washed during a pulse of saturating glutamate and glycine (100 $\mu \mathrm{M}$ each). Individual values of the exponential time-constant $\left(\tau_{\text {off }}\right)$ are indicated. D. Proton inhibition curves. All values of the dose-response 
curve fits and number of cells $(\mathrm{n})$ are listed in Table 1. Proton $\mathrm{IC}_{50}$ values from mutant receptors are not different from that of wt receptors except for GluN2A-P79R ( ${ }^{* \star *}, p=0.0007$, $\mathrm{n}=7$, Bonferroni-corrected two-tailed post hoc t-test).

\section{Figure 3: Effects of GluN2A-P79R and GluN2A-R370W mutations in triheteromeric} NMDARs and in neuronal receptors

A-D. Zinc sensitivity of diheteromeric and triheteromeric NMDARs. Diheteromeric receptors contained either two wild-type (wt) subunits or two mutated subunits. Triheteromeric receptors are either composed of one wt GluN2A subunit and one mutant GluN2A subunit (A and C), or of one wt GluN2B subunit and one mutant GluN2A subunit (B and D). Subunit composition is color-coded as indicated. For triheteromeric receptors values of $\mathrm{IC}_{50}$ and maximal inhibition are, respectively: $17 \pm 1 \mathrm{nM}, 71 \pm 1 \%(\mathrm{n}=8$, GluN1/GluN2AP79R/GluN2Awt); $251 \pm 105$ nM, $75 \pm 8 \%$ (n=7, GluN1/GluN2A-P79R/GluN2Bwt); $18.6 \pm 7.4$ $n M, 73 \pm 9 \%(n=8$, GluN1/GluN2Awt/GluN2Bwt); $2.8 \pm 1$ nM, $89 \pm 4 \%(n=9$, GluN1/GluN2AR370W/GluN2Awt); $1.3 \pm 0.1 \mathrm{nM}, 66 \pm 3 \%$ ( $\mathrm{n}=5$, GluN1/GluN2A-R370W/GluN2Bwt). For diheteromeric receptors, values are $461 \pm 29 \mathrm{nM}, 100 \%(\mathrm{n}=7$, GluN1/GluN2B) and see Table 1. E. Zinc inhibition recordings from rat hippocampal cultured neurons transfected with wt or mutant GluN2A subunits. Zinc was applied at $20 \mathrm{nM}$ (P79R mutant) or $2 \mathrm{nM}$ (R370W). Each trace is an average of $5-10$ individual current traces. ${ }^{* \star *}, p=0.00006(P 79 R, n=7), p=0.0003$ (R370W, n=6), Student's t-test.

\section{Figure 4: Structural interactions of residues GluN2A-P79 and GluN2A-R370}

Homology model of the GluN1/GluN2A NTD dimer based on the GluN1/GluN2B NTD crystal structure (Lee et al., 2014)). The GluN1 and GluN2A NTDs are represented in light yellow and light blue, respectively. The location of the putative high-affinity GluN2A-specific zinc binding site is colored red with residues thought to directly coordinating zinc highlighted. A. 
Residue GluN2A-R370 makes multiple interactions with backbone carbonyls of a lower lobe loop that contains a glutamate residue (GluN2A-E266) critically involved in high-affinity zinc inhibition. B. Residue GluN2A-P79 is buried at a hydrophobic interface between GluN1 and GluN2A NTD upper lobes where it engages multiple Van der Waals interactions with neighboring residues.

Table 1: Effects of GluN2A mutations on NMDAR activation and pharmacological properties

Values: mean \pm SD (number of recorded cells). 


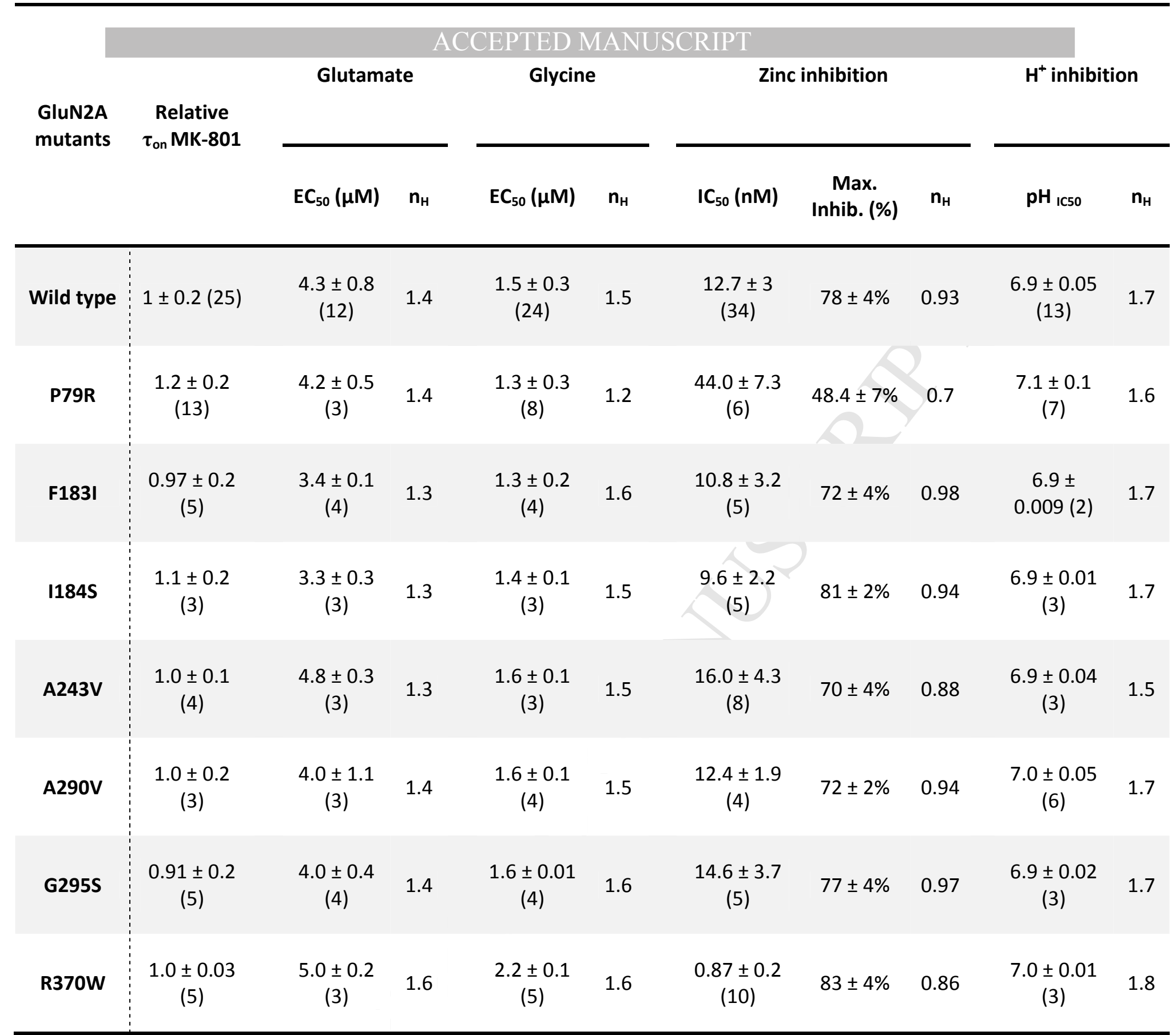


A
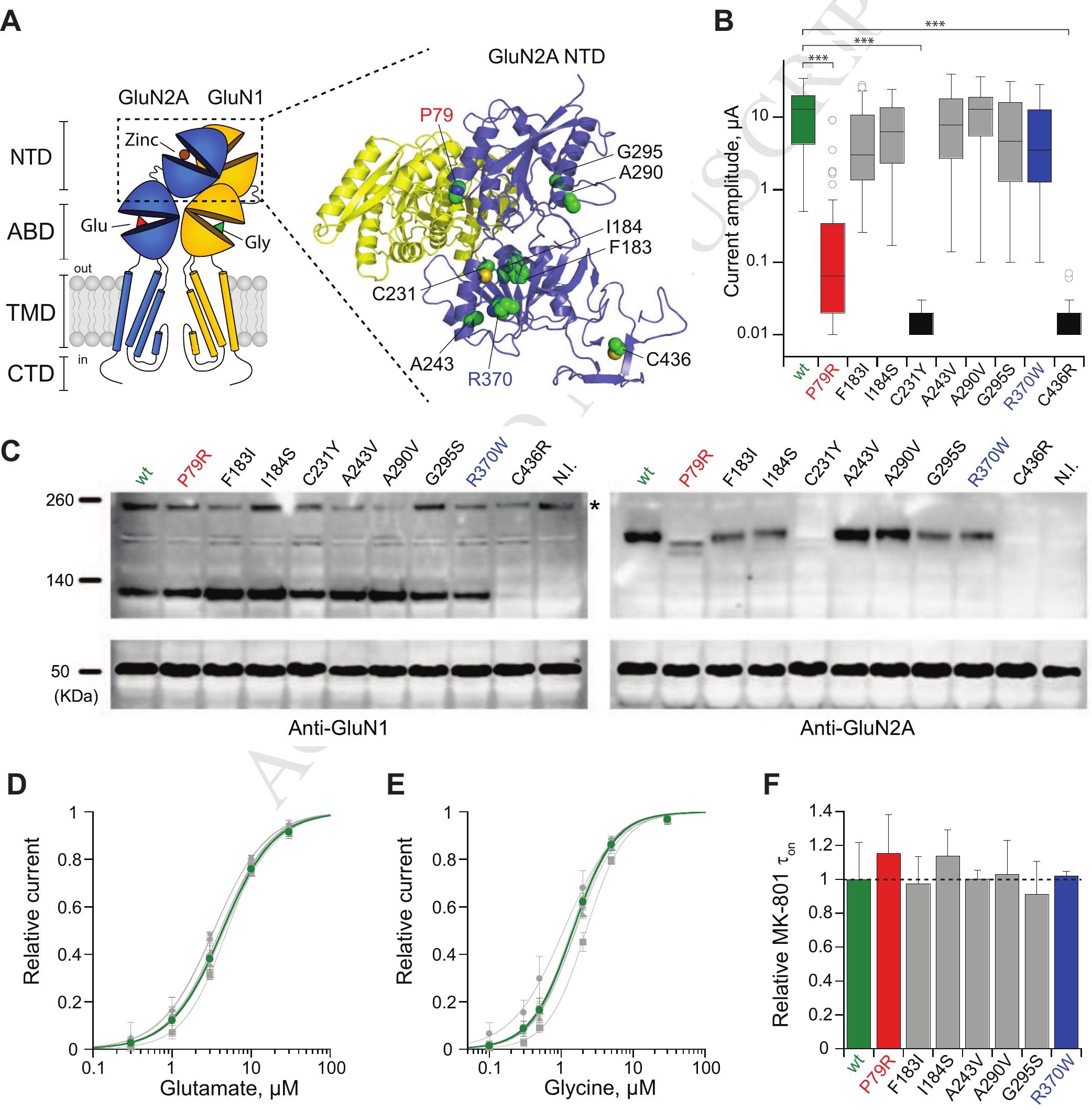
A

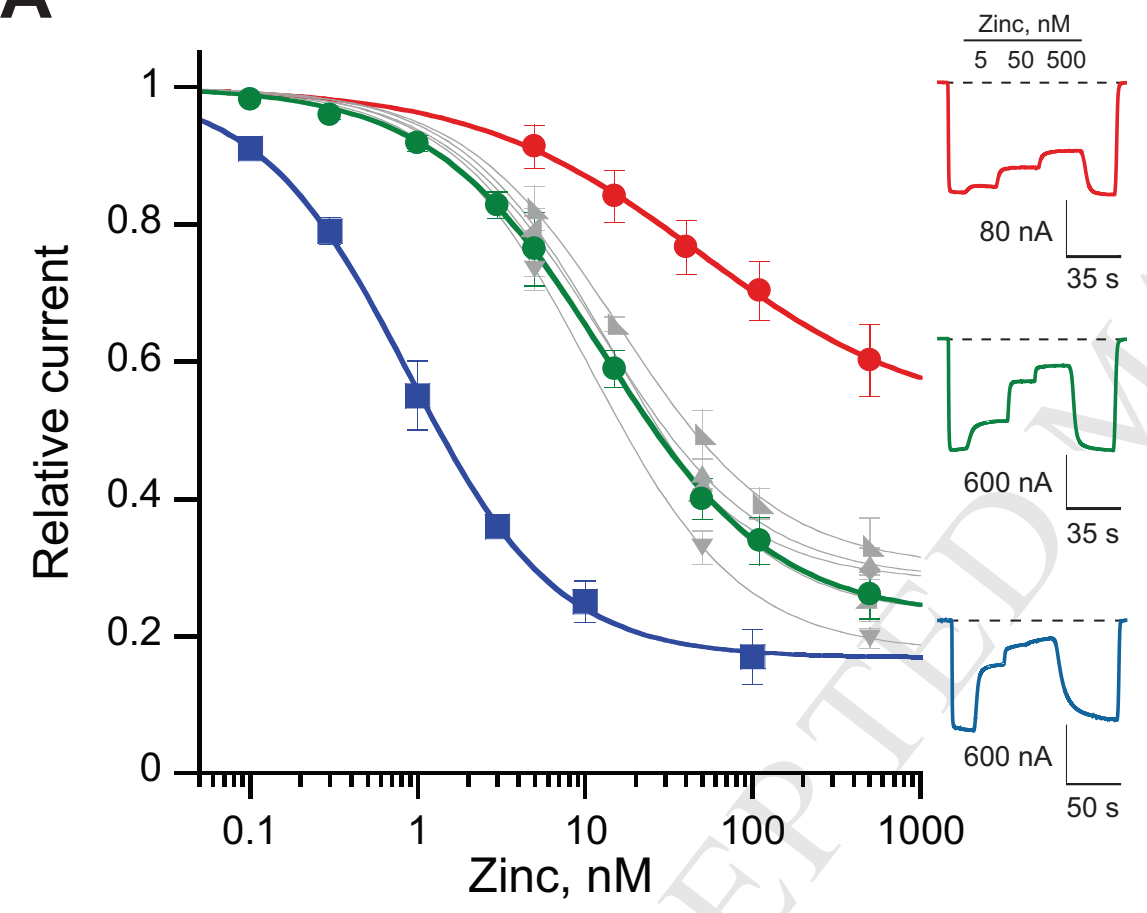

B

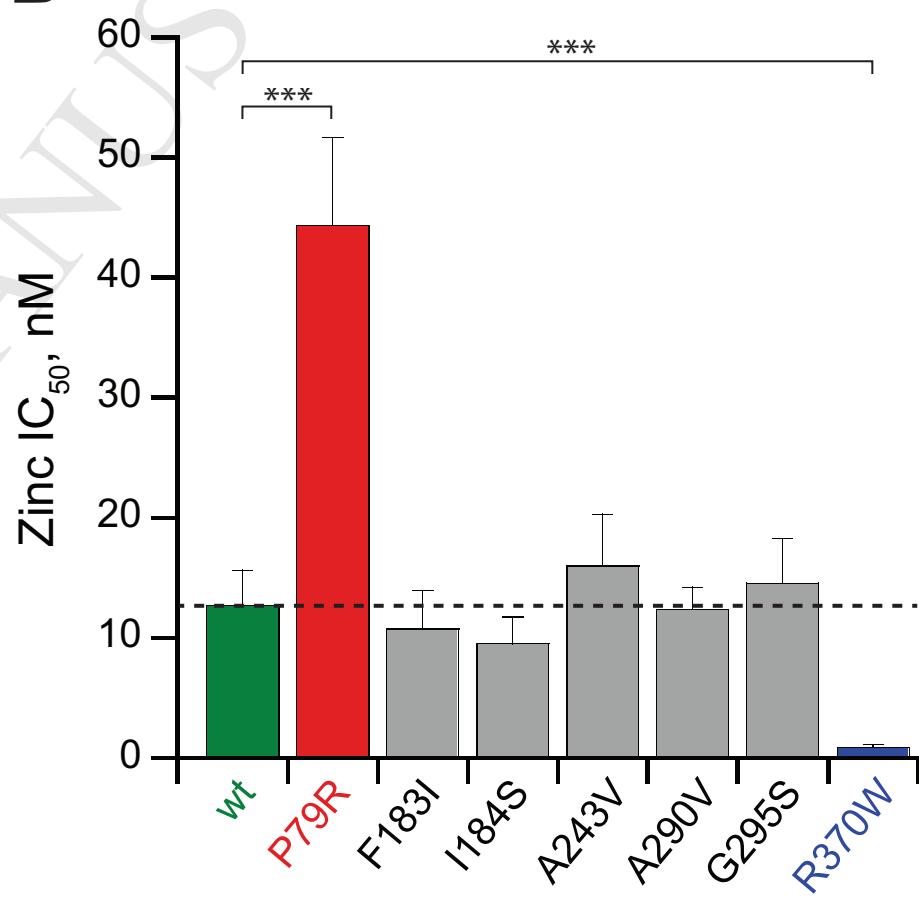

Zinc $40 \mathrm{nM} \quad$ Glu + Gly

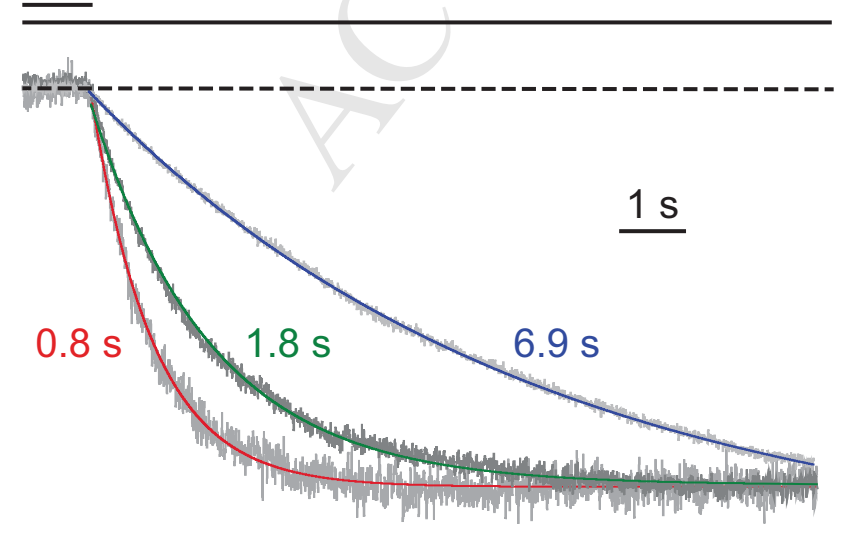

- WT - P79R - R370W

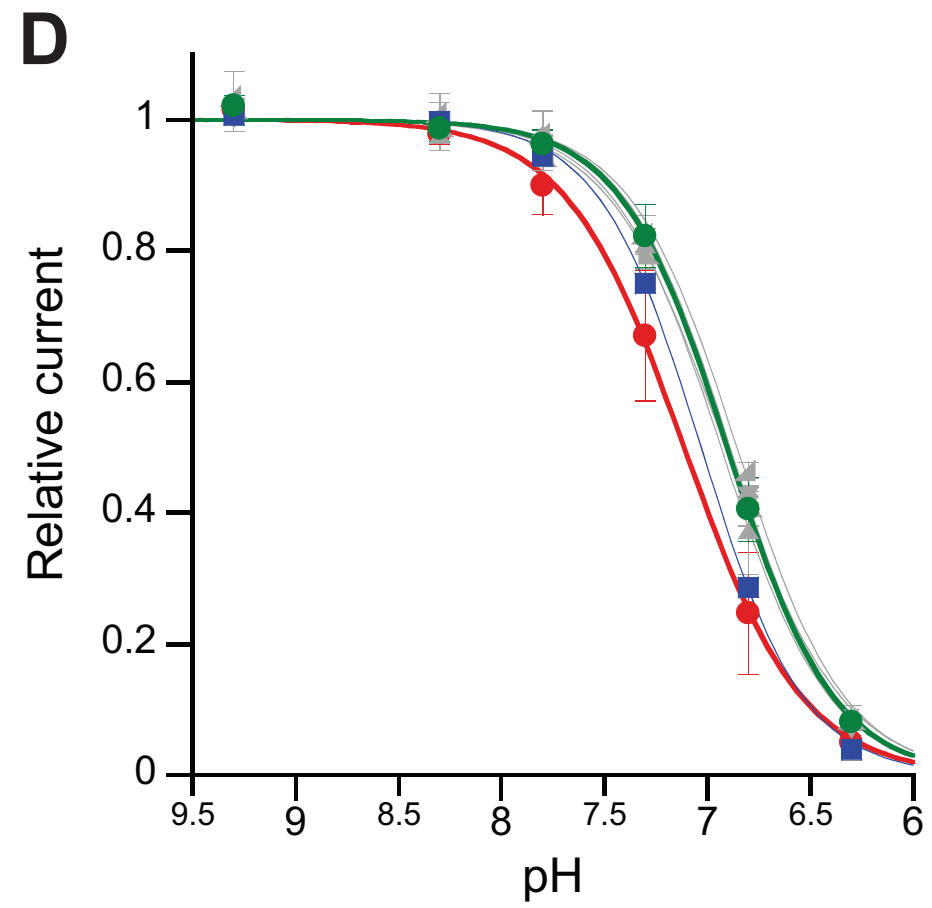


A

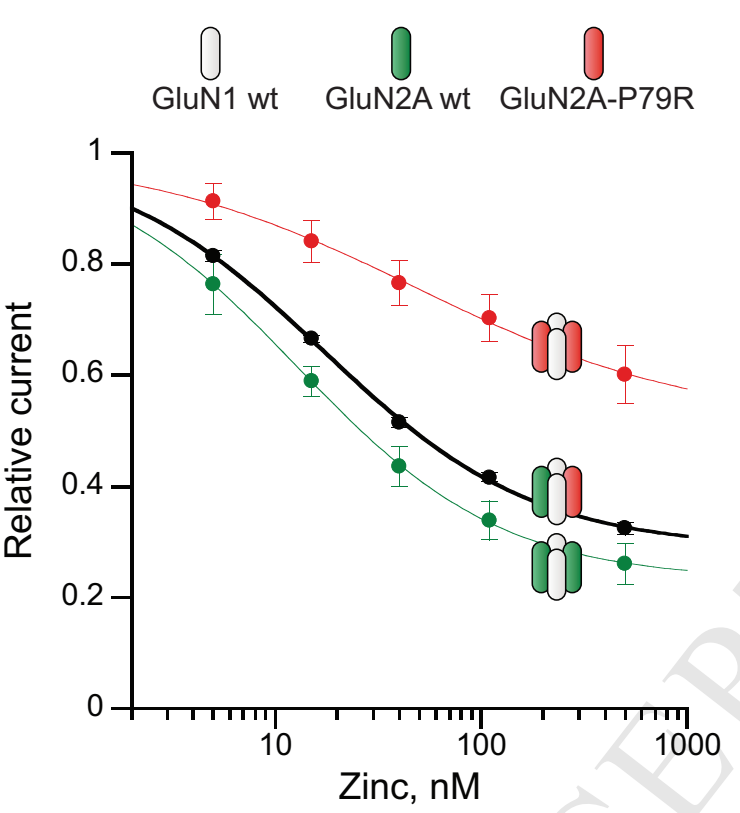

B

$\bigcap_{\text {GluN1 wt }} \overbrace{\text { GluN2A wt GluN2B wt GluN2A-P79R }}$

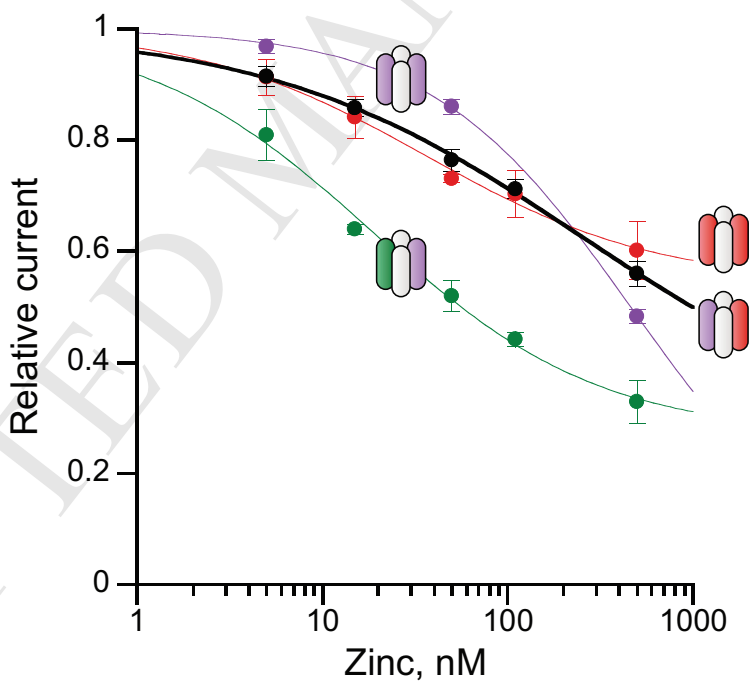

D
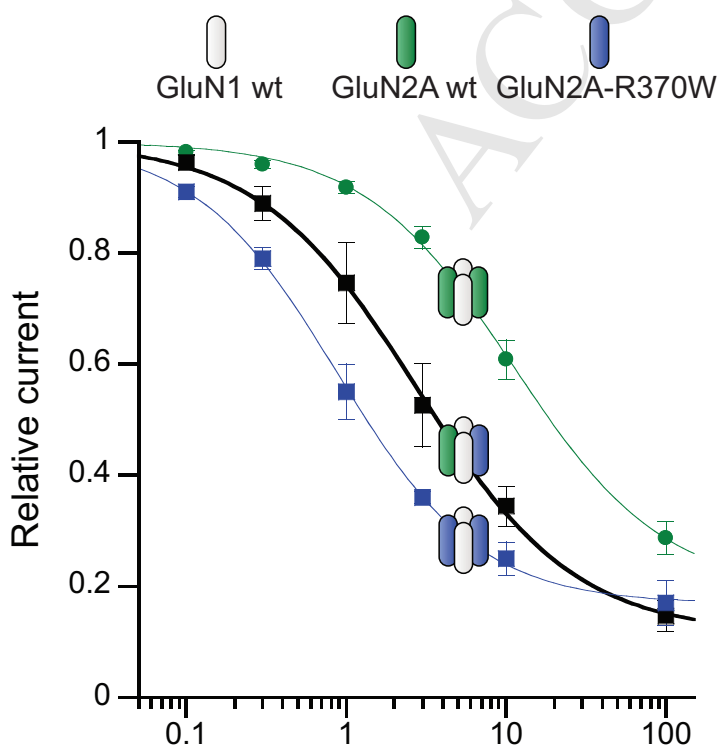

Zinc, nM
E Hippocampal neurons
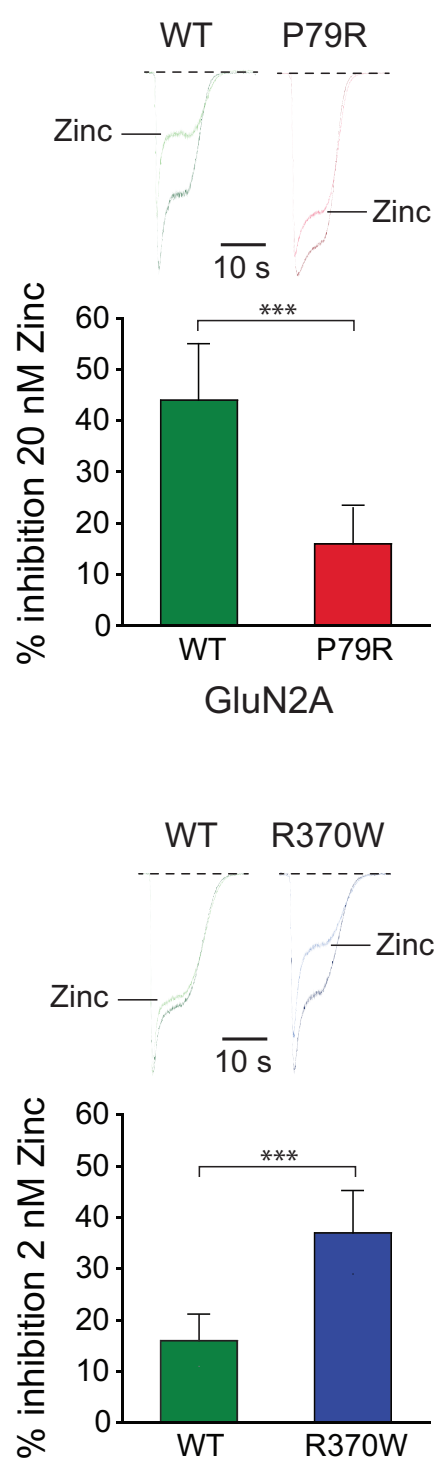

GluN2A 
A

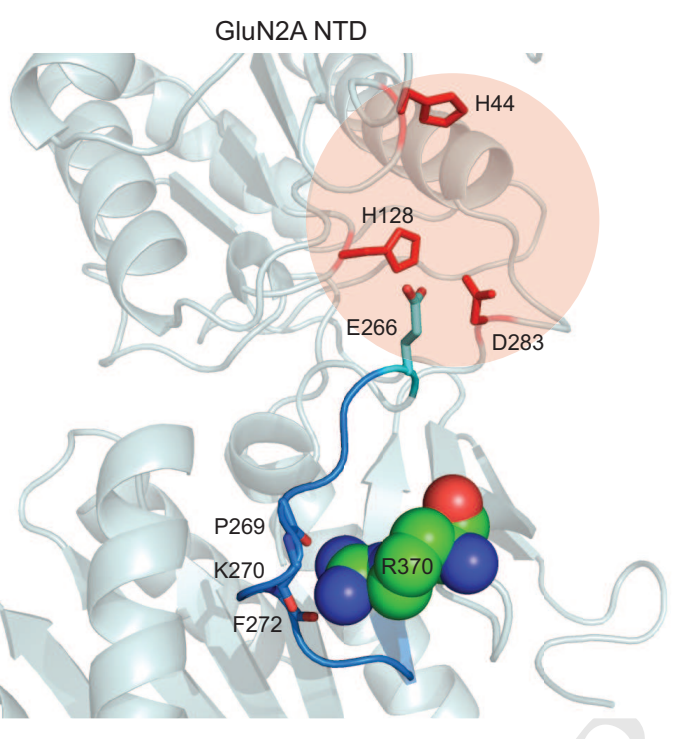

B

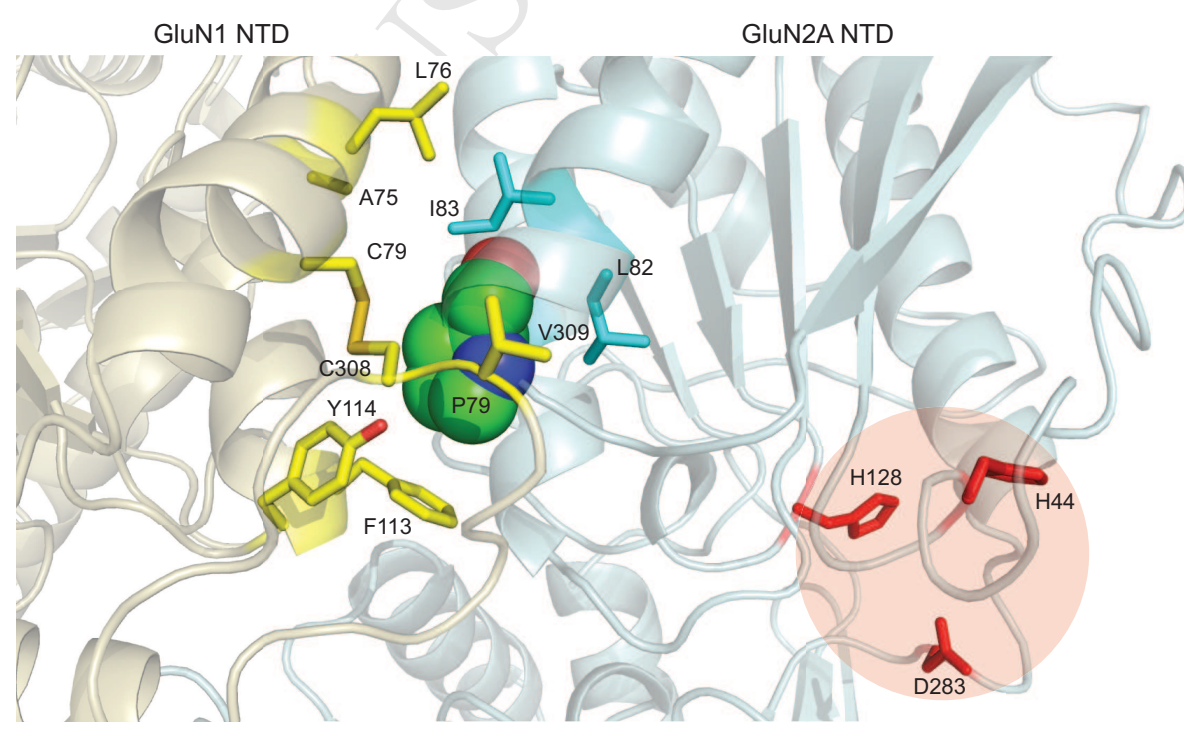


Serraz et al.

Ms \# NEUROPHARM-D-16-00273

\section{Highlights}

- Mutations in NMDAR subunits have recently been associated to human brain disorders

- Eleven missense mutations targeting the GluN2A N-terminal domain were studied

- None of the mutations affect the receptor's basic gating properties

- Distinct alterations in receptor expression and zinc sensitivity were observed

- These results point to an important role of synaptic zinc in human health 